\title{
Nationwide study of Escherichia coli producing extended-spectrum $\beta$-lactamases TEM, SHV and CTX-M in Turkey
}

\author{
Aysegul Copur Cicek ${ }^{1}$, Aysegul Saral ${ }^{2}$, Azer Ozad Duzgun ${ }^{3}$, Ekrem Yasar ${ }^{4}$, Zeynep Cizmeci ${ }^{5}$, \\ Pervin Ozlem Balci ${ }^{6}$, Fatma Sari ${ }^{7}$, Mehmet Firat ${ }^{8}$, Yasemin AY ALTINTOP ${ }^{9}$, Sibel AK ${ }^{10}$, Ahmet Caliskan ${ }^{11}$, \\ Nazan Yildiz ${ }^{12}$, Metin Sancaktar ${ }^{13}$, Emine Esra Budak ${ }^{14}$, Ayse Erturk ${ }^{1}$, Osman Birol Ozgumus ${ }^{1}$ \\ and Cemal Sandalli ${ }^{14}$
}

Four hundred and forty extended-spectrum $\beta$-lactamase (ESBL)-producing Escherichia coli isolates were collected from 10 different hospitals in Turkey between 2011 and 2012. Clinical specimens consisted of urine $(80.45 \%)$, blood (6.59\%), cerebrospinal fluid $(1.13 \%)$, pleural fluid $(2.95 \%)$, wound $(4.31 \%)$ and sputum $(4.54 \%)$. ESBL-coding genes (CTX-M1, CTX-M2, TEM, SHV were detected by PCR. According to the PCR and sequencing results, CTX-M1 was the most prevalent $\beta$-lactamase $83.18 \%$ (366/440), followed by TEM 44.09\% (194/440), CTX-M2 31.81\% (140/440) and SHV $1.81 \%(8 / 440)$. Sequencing results showed that TEM and SHV types were TEM-1b and SHV-11, respectively. Rate of the strains harboring only CTX-M1, CTX-M2, TEM-1b and SHV-11 were $30.90 \%, 3.63 \%, 2.27 \%$ and $0.23 \%$, respectively. Rate of the strains harboring the combinations of CTX-M1-CTX-M2, CTX-M1-CTX-M2-TEM-1b, CTX-M2-TEM-1b, CTX-M1-TEM-1b, CTX-M1-CTX-M2-TEM1b-SHV-11, CTX-M1-TEM-1b-SHV-11, CTX-M1-SHV-11, CTX-M1-CTX-M2-SHV-11, CTX-M2-SHV-11, CTX-M2-TEM-1b-SHV-11, TEM-1b-SHV-11 were $12.95 \%, 11.59 \%, 2.95 \%, 26.13 \%, 0.45 \%, 0.68 \%, 0.22 \%, 0.22 \%, 0 \%, 0 \%$ and $0 \%$, respectively. This is a nationwide study of ESBL-producing $E$. coli in Turkey. These results shows that CTX-M1 group is the most common type of class A $\beta$-lactamases among ESBL-producing E. coli strains in Turkey.

The Journal of Antibiotics (2013) 66, 647-650; doi:10.1038/ja.2013.72; published online 10 July 2013

Keywords: $\beta$-lactamase; CTX-M1; CTX-M2; SHV-11; TEM-1b

\section{INTRODUCTION}

Extended-spectrum $\beta$-lactamases (ESBLs)-producing members of Enterobacteriaceae are resistant to penicillins, narrow and extended spectrum cephalosporins and aztreonam. They are also often resistant to aminoglycosides, trimethoprim-sulfamethoxazole and quinolones. ${ }^{1}$ ESBL-producing organisms, such as Klebsiella pneumoniae, Escherichia coli, Morganella morganii, Serratia marcescens, Shigella dysenteriae, several species of Enterobacter, Salmonella, Proteus, Citrobacter, Pseudomonas aeruginosa, Burkholdeia cepacia and Capnocytophaga ochracea, have been reported in many countries. ${ }^{2}$

ESBL-producing E. coli has emerged worldwide as a significant cause of community and healthcare-associated infections. ${ }^{3}$ Extended- spectrum $\beta$-lactamases are grouped into four classes A, B, C and D enzymes. Enzymes of classes $\mathrm{A}, \mathrm{C}$ and $\mathrm{D}$ are active site serine enzymes, whereas the class B enzymes are Zn-metalloenzymes. TEM, SHV and CTX-M are class A ESBLs. ${ }^{4}$ Mutations in TEM and SHV structural genes cause development of new enzymes. ${ }^{5}$ TEM and sulphydryl variable SHV are the major types. However, CTX-M type has emerged among the ESBL-producing organisms. CTX-M $\beta$-lactamases have been classified into five groups 1, 2, 8, 9 and $25 / 26$ according to their amino-acid sequence similarities. ${ }^{6}$ CTX-Mproducing strains show worldwide dissemination. ${ }^{7}$ Whereas group 1 has involved CTX-M1, $-3,-10,-11,-12,-15,-22,-23,-27,-28,-29$, $-30,-32,-33,-34,-36,-37$ and -42 , group 2 has involved CTX-M2, -4 , $-5,-6,-7,-20,-31,-35$ and Toho- $1 .^{8}$

${ }^{1}$ Department of Medical Microbiology, Faculty of Medicine, Recep Tayyip Erdogan University, Rize, Turkey; ${ }^{2}$ Department of Biology, Faculty of Arts and Sciences, Artvin Coruh University, Artvin, Turkey; ${ }^{3}$ Department of Biology, Faculty of Arts and Sciences, Giresun University, Giresun, Turkey; ${ }^{4}$ Laboratory of Microbiology, Diyarbakir Pediatrics Hospital, Diyarbakır, Turkey; ${ }^{5}$ Department of Medical Microbiology, Kecioren Training and Research Hospital, Ankara, Turkey; ${ }^{6}$ Laboratory of Microbiology, Tokat State Hospital, Tokat, Turkey; ${ }^{7}$ Laboratory of Microbiology, Denizli Servergazi State Hospital, Denizli, Turkey; ${ }^{8}$ Ozel OSM Ortadogu Hospital, Infectious Diseases and Clinical Microbiology, Sanlıurfa, Turkey:; ${ }^{9}$ Laboratory of Microbiology, Nigde State Hospital, Nigde, Turkey; ${ }^{10}$ Laboratory of Microbiology, Malatya State Hospital, Malatya, Turkey; ${ }^{11}$ Laboratory of Microbiology, Kahramanmaras Necip Fazıl State Hospital, Kahramanmaras, Turkey; ${ }^{12}$ Laboratory of Microbiology, Konya Beyhekim State Hospital, Konya, Turkey; ${ }^{13}$ Laboratory of Microbiology, Trabzon Hackali Baba State Hospital, Trabzon, Turkey and ${ }^{14}$ Microbiology and Molecular Biology Research Laboratory, Department of Biology, Faculty of Arts and Sciences, Recep Tayyip Erdogan University, Rize, Turkey

Correspondence: Dr C Sandalli, Microbiology and Molecular Biology Research Laboratory, Department of Biology, Faculty of Arts and Sciences, Recep Tayyip Erdogan University, Rize 53100, Turkey.

E-mail: cemal.sandalli@erdogan.edu.tr

Received 29 January 2013; revised 31 May 2013; accepted 11 June 2013; published online 10 July 2013 
The diversity and increasing prevalence of TEM, SHV and CTX-Mtype of ESBLs pose serious threat to the clinical use of thirdgeneration cephalosporins for the treatment of severe infections. Determination of the genes encoding for ESBLs by PCR and sequencing can supply useful data about their molecular epidemiology and risk factors associated with these infections. ${ }^{5}$

The prevalence of ESBLs is over $10 \%$ in Hungary, Poland, Romania, Russia and Turkey. In Turkey, CTX-M-15 is widely distributed, and epidemic strains of $K$. pneumoniae isolates producing the carbapenemase OXA- 48 and SHV-12 or CTX-M-15 type of ESBLs have emerged. ${ }^{9}$ In one study from Turkey, TEM- and CTX-M-type ESBLs were found in $72 \%$ and $22 \%$ of ESBL-producing E. coli $(n=44)$, respectively. ${ }^{5}$ One study from America showed that ESBL strains included SHV-2, 5, CTX-M, and even non-TEM and nonSHV was not spread geographically. There have been a number of outbreaks of ESBL-producing infections in Africa and the Middle East. Studies from several countries including China, India, Japan, Korea and Malaysia showed ESBL-producing strains ranging from 30 to $40 \%$. CTX-M-type ESBL is predominant in countries like India, China Korea, Japan and Taiwan. ${ }^{10}$ The blaCTX-M-15 genes are predominant in ESBL-producing strains in a study from France. ${ }^{11}$ ESBL-producing E. coli strains isolated from Austria and Italy showed that they expressed CTX-M group I enzymes predominantly. ${ }^{12}$ Molecular characterization of ESBLs in 440 E. coli isolates from 10 centers between 2011 and 2012 was examined. Molecular analyses of particular ESBL types on a national level performed in district hospitals have contributed to a better understanding of the epidemiology of the strains producing these enzymes at local, national and international level. ${ }^{9}$

\section{MATERIALS AND METHODS}

\section{Bacterial isolates}

Nonrepeat ESBL-producing E. coli isolates were collected between 2011 and 2012 from 10 different Turkish medical centers; Trabzon and Tokat (Black Sea Region), Sanliurfa, Diyarbakir and Malatya (South-East Anatolia Region), Nigde, Konya and Ankara (Central Anatolia Region), Kahramanmaras (Mediterranean Region) and Denizli (Aegean region). ESBL production was confirmed phenotypically by using the Clinical and Laboratory Standards Institute criteria for ESBL screening and disk confirmation tests. The most of the ESBL-producing isolates were recovered from urine specimens (Table 1).

\section{DNA extraction}

Genomic DNA used as a template for PCR assays was obtained from bacterial suspension grown overnight in Luria Broth with shaking incubator at $37^{\circ} \mathrm{C}$.

Table 1 Clinical specimen of ESBL-producing $E$. coli isolates

\begin{tabular}{|c|c|c|c|c|c|c|c|}
\hline Centers & $\begin{array}{l}\text { Strain } \\
\text { number } \\
\text { (n) }\end{array}$ & $\begin{array}{l}\text { Urine } \\
\text { (n) }\end{array}$ & $\begin{array}{l}\text { Blood } \\
\text { (n) }\end{array}$ & $\begin{array}{c}\operatorname{CSF}( \\
\mathrm{n})\end{array}$ & $\begin{array}{l}\text { Pleural } \\
\text { Fluid } \\
\text { (n) }\end{array}$ & $\begin{array}{c}\text { Wound } \\
\text { (n) }\end{array}$ & $\begin{array}{c}\text { Sputum } \\
\text { (n) }\end{array}$ \\
\hline Malatya & 26 & 22 & 1 & - & 1 & 1 & 1 \\
\hline Denizli & 36 & 30 & 1 & - & - & 4 & 1 \\
\hline Diyarbakir & 36 & 27 & 4 & 1 & 2 & 2 & - \\
\hline Trabzon & 74 & 58 & 6 & 1 & 2 & 4 & 3 \\
\hline Konya & 64 & 56 & 3 & - & 1 & 2 & 2 \\
\hline Nigde & 15 & 13 & 1 & - & - & - & 1 \\
\hline Ankara & 64 & 45 & 6 & 2 & 3 & 3 & 5 \\
\hline Tokat & 42 & 34 & 4 & - & 1 & 1 & 2 \\
\hline Sanliurfa & 51 & 41 & 2 & 1 & 2 & 1 & 4 \\
\hline Kahramanmaras & 32 & 28 & 1 & - & 1 & 1 & 1 \\
\hline
\end{tabular}

Abbreviations: CSF, cerebrospinal fluid; ESBL, extended-spectrum $\beta$-lactamase.
Bacterial suspension was centrifuged at 13000 r.p.m. for $5 \mathrm{~min}$. Pellet was suspended in $500 \mu \mathrm{l}$ distilled water and subsequently boiled in a water bath for $10 \mathrm{~min}$. Debris was centrifuged at 13000 r.p.m. for $5 \mathrm{~min}$. Five hundred microlitres of supernatant was used as the template for PCR assays. ${ }^{13}$

\section{Multiplex PCR for detection $C T X-M$ genes}

Multiplex PCR was used for detecting CTX-M1 and CTX-M2 group $\beta$-lactamases. ${ }^{8}$ Primers used for detection $b$ la $_{\mathrm{CTX}-\mathrm{M}}$ genes are shown in Table 2. PCRs were performed in a final volume of $50 \mu$ l. PCR mix component was as follows; $5 \mu \mathrm{l}$ of genomic DNA, $20 \mathrm{pM}$ of each primer, $10 \mu \mathrm{l}$ reaction buffer (Promega, Madison, WI, USA), $3 \mu \mathrm{l} 25 \mathrm{~mm} \mathrm{MgCl} 2,200 \mu \mathrm{M}$ of each dNTPs and 1.5 U of Taq Polymerase (Promega). PCR amplification condition was as follows: initial denaturation at $95^{\circ} \mathrm{C}$ for $2 \mathrm{~min}$ followed by 30 cycles of $1 \mathrm{~min}$ at $95^{\circ} \mathrm{C}, 1 \mathrm{~min}$ at $55^{\circ} \mathrm{C}$ and $1 \mathrm{~min}$ at $72^{\circ} \mathrm{C}$, with a final extension of 10 min at $72^{\circ} \mathrm{C}$.

\section{Detection of $\boldsymbol{b l a} a_{\mathrm{TEM}}$ and $\boldsymbol{b l a} \boldsymbol{a}_{\mathrm{SHV}}$ genes}

The primers used to amplify the $b l a_{\text {TEM }}$ and $b l a_{\text {SHV }}$ genes are listed in Table 2. A single reaction mixture contained: $5 \mu \mathrm{l}$ of genomic DNA, $20 \mathrm{pM}$ of each primer, $10 \mu \mathrm{l}$ reaction buffer (Promega), $3 \mu \mathrm{l} 25 \mathrm{mM} \mathrm{MgCl}_{2}, 200 \mu \mathrm{M}$ of dNTPs and 1.5 of U Go Taq Flexi Polymerase (Promega) in a final volume of $50 \mu$ l. PCR amplification condition was as follows: initial denaturation at $95^{\circ} \mathrm{C}$ for $5 \mathrm{~min}$ followed by 35 cycles of $45 \mathrm{~s}$ at $95^{\circ} \mathrm{C}, 45 \mathrm{~s}$ at $56^{\circ} \mathrm{C}$ for $b a_{\mathrm{TEM}}$, and $55^{\circ} \mathrm{C}$ for bla $a_{\mathrm{SHV}}$ and $1 \mathrm{~min}$ at $72{ }^{\circ} \mathrm{C}$, with a final extension of $10 \mathrm{~min}$ at $72^{\circ} \mathrm{C}$. All PCR results were analyzed on $1 \%$ agarose containing $0.5 \mu \mathrm{g} \mathrm{ml}^{-1}$ ethidium bromide, and subsequently visualized under ultraviolet light. The PCR products were sent to Macrogen, Seoul, Korea for sequencing by using the same primers used in PCR reactions. Sequencing results were analyzed using alignment search tool, BLAST (http://www.ncbi.nlm.nih.gov/BLAST) ${ }^{14}$ and the multiple sequence alignment program, CLUSTALW2(http://www.ebi.ac.uk/Tools/msa/clustalw2/).

\section{RESULTS}

ESBL-producing isolates were collected from Trabzon $(n=74)$, Sanliurfa $(n=51)$, Diyarbakir $(n=36)$, Konya $(n=64)$, Ankara $(n=64)$, Kahramanmaras $(n=32), \quad$ Denizli $\quad(n=36)$, Tokat $(n=42)$, Nigde $(n=15)$ and Malatya $(n=26)$.

Of the 440 ESBL-producing E. coli isolates, 366 (83.18\%) were positive for CTX-M1 group enzymes, $140(31.81 \%)$ were positive for CTX-M2 group enzymes, whereas 8 (1.81\%) produced SHV and 194 $(44.09 \%)$ produced TEM-type $\beta$-lactamase. The sequencing result of TEM and SHV showed all TEM- and SHV-type $\beta$-lactamases were TEM-1b and SHV-11, respectively. Some of the CTX-M-producing isolates also produced SHV and TEM $\beta$-lactamases. As expected, there was a predominance of CTX-M-producing organisms mostly isolated from urine specimens.

The geographical distribution of ESBLs in Turkey is shown in Figure 1. CTX-M1 group ESBLs were found in 71.62\%, $90.19 \%$, $83.33 \%, 89.06 \%, 75 \%, 93.75 \%, 91.66 \%, 83.33 \%$, 93.33\% and $76.92 \%$

Table 2 Primers used in study to amplify the ESBL genes

\begin{tabular}{|c|c|c|c|c|}
\hline \multirow[b]{2}{*}{ Primers } & \multirow[b]{2}{*}{$5^{\prime} \rightarrow 3^{\prime}$} & \multicolumn{2}{|c|}{ Amplicon } & \multirow[b]{2}{*}{ References } \\
\hline & & Size & $\mathrm{T}_{m}{ }^{\circ} \mathrm{C}$ & \\
\hline \multirow[t]{2}{*}{ CTX-M1 } & F: GCGTGATACCACTTCACCTC & & & \\
\hline & R: TGAAGTAAGTGACCAGAATC & 260 & & 8 \\
\hline \multirow[t]{2}{*}{ CTX-M2 } & F: TGATACCACCACGCCGCTC & & & \\
\hline & R: TATTGCATCAGAAACCGTGGG & 341 & 55 & 8 \\
\hline \multirow[t]{2}{*}{ TEM } & F: AGTATTCAACATTTYCGTGT & & & \\
\hline & R: TAATCAGTGAGGCACCTATCTC & 847 & 56 & This study \\
\hline \multirow[t]{2}{*}{ SHV } & F: ATGCGTTATATTCGCCTGTG & & & \\
\hline & R: TTAGCGTTGCCAGTGCTC & 843 & 55 & 2 \\
\hline
\end{tabular}

Abbreviation: ESBL, extended-spectrum $\beta$-lactamase; Tm, melting temperature. 


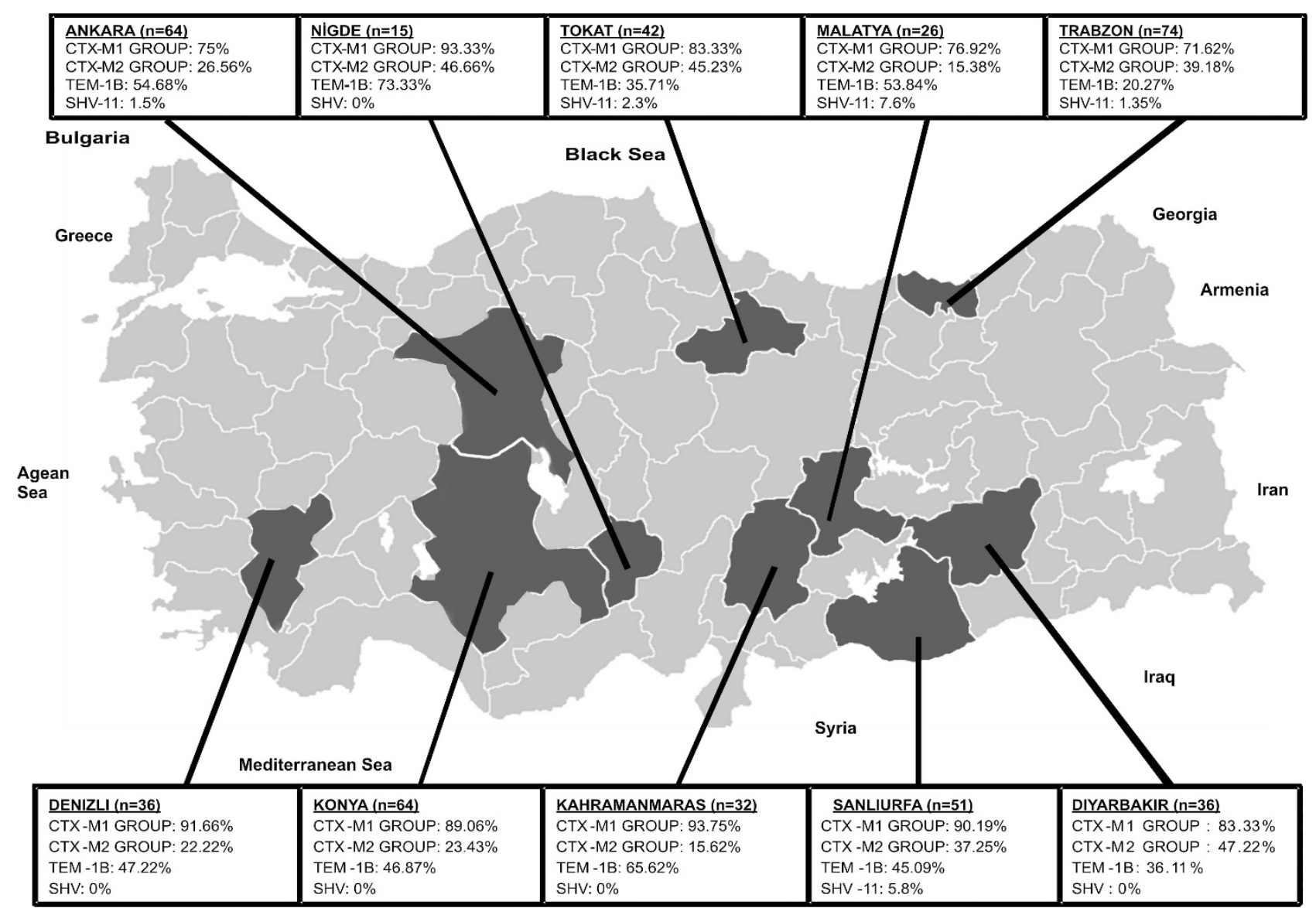

Figure 1 The geographical distribution of ESBLs (CTX-M1, CTX-M2, TEM-1b and SHV-11) in Turkey.

of isolates from Trabzon, Sanliurfa, Diyarbakir, Konya, Ankara, Kahramanmaras, Denizli, Tokat, Nigde and Malatya, respectively. CTX-M2 group ESBLs were found in $39.18 \%, 37.25 \%, 47.22 \%$, $23.43 \%, 26.56 \%, 15.62 \%, 22.22 \%, 45.23 \%, 46.66 \%$ and $15.38 \%$ of isolates from Trabzon, Sanliurfa, Diyarbakir, Konya, Ankara, Kahramanmaras, Denizli, Tokat, Nigde and Malatya, respectively. TEM-1b-type ESBLs were found in 20.27\%, 45.09\%, 36.11\%, 46.87\%, $54.68 \%, 65.62 \%, 47.22 \%, 35.71 \%, 73.33 \%$ and $53.84 \%$ of isolates from Trabzon, Sanliurfa, Diyarbakir, Konya, Ankara, Kahramanmaras, Denizli, Tokat, Nigde and Malatya, respectively. SHV-11-type ESBLs were found in $1.35 \%, 5.8 \%, 0 \%, 0 \%, 1.5 \%, 0 \%, 0 \%, 2.3 \%, 0 \%$ and $7.6 \%$ of isolates from Trabzon, Sanliurfa, Diyarbakir, Konya, Ankara, Kahramanmaras, Denizli, Tokat, Nigde and Malatya, respectively. Rate of the strains harboring only CTX-M1, CTX-M2, TEM-1b and SHV-11 were $30.90 \%, 3.63 \%, 2.27 \%$ and $0.23 \%$, respectively. Rate of the strains harboring the combinations CTX-M1-CTX-M2, CTX-M1-CTX-M2-TEM-1b, CTX-M2-TEM-1b, CTX-M1-TEM-1b, CTX-M1-CTX-M2-TEM-1b-SHV-11， CTX-M1-TEM-1b-SHV-11, CTX-M1-SHV-11, CTX-M1-CTX-M2-SHV-11, CTX-M2-SHV-11, CTX-M2-TEM-1b-SHV-11, TEM-1b-SHV-11 were $12.95 \%, 11.59 \%$, $2.95 \%, 26.13 \%, 0.45 \%, 0.68 \%, 0.22 \%, 0.22 \%, 0 \%, 0 \%$ and $0 \%$, respectively.

\section{DISCUSSION}

E. coli isolates are present in normal human fecal flora. However, some strains can cause gastroenteritis and food born diseases.
In addition, E. coli isolates are also the causative agents of the blood-stream infection, lower respiratory tract infection, wound and abscess infection. Most importantly, E. coli is the most common cause of urinary tract infections. The most common mechanism of resistance to $\beta$-lactam antibiotics in $E$. coli is $\beta$-lactamase production. ${ }^{15}$ TEM, SHV and CTX-M are class A ESBLs. CTX-M enzymes have only $40 \%$ similarity to TEM and SHV. ${ }^{7}$ TEM or SHV $\beta$-lactamase derivatives have been the most prevalent types of ESBLs among nosocomial pathogens since the 1980s. However, starting from 1995 onwards, CTX-M type has started to increase dramatically in most parts of the world, such as Europe, Asia, South America and North America, expect in the United States. ${ }^{16}$

We studied the rate of the TEM-, SHV- and CTX-M-type $\beta$-lactamases in E. coli from 10 centers in Turkey. We found CTXM1 as the most prevalent (83.18\%) ESBL followed by TEM-1b (44.09\%), CTX-M2 (31.81\%) and SHV-11 (1.81\%). High prevalence of CTX-M1 group enzymes were shown in ESBL-producing E.coli in Italy against TEM, CTX-M2 and SHV types. ${ }^{17}$ Similarly, a study showed CTX-M enzymes were the most prevalent ESBL types isolated from E. coli in Spain. ${ }^{1}$ One study identified that $41 \%$ of the CTX-M14-positive urinary E. coli isolates were from the patients with no history of previous hospitalization. ${ }^{18}$ Another Spanish study investigated 151 ESBL-producing E. coli isolates, and $50.3 \%$ of these isolates were involved in urinary tract infections and $88 \%$ of them expressed CTX-M-15. ${ }^{19}$ 
In 1997, SHV-11 was found as a novel variant of SHV $\beta$-lactamases carrying a leucine-to-glutamine substitution at position 35. This point mutation is far from the active site so that SHV-11 and SHV-2a show same activity. ${ }^{20}$ SHV-12, SHV-5, SHV-2, SHV-2a, SHV-31 and SHV-38 have been reported in HITIT-2 study from Turkey. ${ }^{21}$

In a previous study from Turkey between 2004 and 2005 years, the rate of CTX-M-type ESBL in isolates was determined as $71.4 \% .^{22}$ Another study was performed between 2002 and 2003 from seven centers and the rate of CTX-M prevalence in E. coli strains were determined as $76 \% .{ }^{23}$ According to these results, approximately after 10 years, our results almost indicate the similar ratio for CTX-M prevalence in E. coli. Although we did not investigate by any survey, it could be thought that socioeconomic backgrounds of the people living in those regions might be have an impact on the situations affecting these prevalence. In a different study, the prevalence of CTX$\mathrm{M}$, TEM and SHV were determined as 93\%, 64\% and $11 \%$, respectively. In the same study, CTX-M and TEM were found together in 52\%, CTX-M, TEM and SHV were found together in $5 \%$, and CTX-M and SHV were found as $1.78 \%$ ratio. ${ }^{23}$ According to our data, the combination ratio of CTX-M1 and TEM is $26.13 \%$, CTX-M1, TEM and SHV is $0.68 \%$, and CTX-M and SHV is $0.22 \%$. High CTX-M rate in our study is consistent with the increasing incidence of CTX-M type of $\beta$-lactamases in our country and all over the world.

Antimicrobial therapy is very important in the treatment of urinary tract infections. However, the drug resistance generated by ESBL-producing microorganisms causes failure in the treatment of infections. $^{24}$ These enzymes can be chromosomal or plasmid mediated and may be carried on integrons. Integrons cause the spread of antimicrobial drug resistance. ${ }^{24}$ Extended-spectrum $\beta$-lactamase-producing organisms should be determined very fast so that infection control precautions can be applied.

This is a nationwide molecular characterization of ESBLs in E. coli isolates from Turkey. In conclusion, the existence of CTX-M, TEM and SHV $\beta$-lactamases is significantly connected with the resistance to penicillins, broad- and extended-spectrum cephalosporins, and aztreonam among ESBL-producing E.coli. In Turkey, CTX-M enzymes are the most prevalent ESBLs and followed by TEM and SHV. Therefore, ESBL-producing E.coli isolates causing urinary tract infections urgently need infection control measures.

\section{CONFLICT OF INTEREST}

The authors declare no conflict of interest.

\section{ACKNOWLEDGEMENTS}

This work was supported by Recep Tayyip Erdogan University Research Fund Grants BAP-2012.106.01.11 and BAP-2011.102.03.3.
1 Jesus, R. B. et al. Epidemiology and clinical features of Infections caused by extended-spectrum beta-lactamase-producing Escherichia coli in nonhospitalized patients. J. Clin. Microbiol. 42, 1089-1094 (2004).

2 Hanson, N. D. et al. Unusual Salmonella enterica serotype Typhimurium isolate producing CMY-7, SHV-9 and OXA-30 $\beta$-lactamases. J. Antimicrob. Chemother. 49, 1011-1014 (2002).

3 Díaz, M. A. et al. For the Spanish Group for Nosocomial Infections (GEIH) Diversity of Escherichia coli strains producing extended-spectrum $\beta$-lactamases in Spain: Second Nationwide Study. J. Clin. Microbiol. 48, 2840-2845 (2010).

4 Shahid, M. et al. blaCTX-M, blaTEM, and blaSHV in Enterobacteriaceae from NorthIndian tertiary hospital: high occurrence of combination genes. Asıan. Pac. J. Trop. Med. 4, 101-105 (2011).

5 Bali, E. B., Acık, L. \& Sultan, N. Phenotypic and molecular characterization of SHV TEM, CTX-M and extended-spectrum $\beta$-lactamase produced by Escherichia coli, Acinobacter baumannii and Klebsiella isolates in a Turkish hospital. Afr. J. Microbiol. Res. 4, 650-654 (2010).

6 Bonnet, R. Growing group of extended-spectrum $\beta$-lactamases: the CTX-M enzymes. Antimicrob. Agents Chemother. 48, 1-14 (2004).

7 Eckert, C. et al. Dissemination of CTX-M-type $\beta$-lactamases among clinical Isolates of Enterobacteriaceae in Paris. France Antimicrob. Agents Chemother. 48, 1249-1255 (2004).

8 Xu, L., Ensor, V., Gossain, S., Nye, K. \& Hawkey, P. Rapid and simple detection of blaCTX-M genes by multiplex PCR assay. J. Med. Microbiol. 54, 1183-1187 (2005).

9 Coque, T. M., Baquero, F. \& Canton, R. Increasing prevalence of ESBL producing Enterobacteriaceae in Europe. Eurosurveillance 13, 1-11 (2008).

10 Antony, S. J. in Clinical Management of Complicated Urinary Tract Infection (Nikibakhsh, Ahmad ed.) 19-22 (InTech, Rijeka, Croatia, 2011).

11 Lavigne, J. P. et al. CTX-M $\beta$-lactamase-producing Escherichia coli in French Hospitals: prevalence, molecular epidemiology, and risk factors. J. Clin. Microbiol. 45, 620-626 (2007).

12 Huemer, H. P., Eigentler, A., Aschbacher, R. \& Larcher, C. Dominance of CTX-M group 1 beta-lactamase enzymes in ESBL producing $E$. coli from outpatient urines in neighboring regions of Austria and Italy. Wien. Klin. Wochenschr 123, 41-44 (2011)

13 Dobrowolski, P. in Short Protocols in Molecular Biology. 2nd edn (eds Ausubel, F. M. et al. John Willey \& Sons, New York, NY, USA, 1992).

14 Altschul, S. F., Gish, W., Miller, W., Myers, E. W. \& Lipman, D. J. Basic local alignment search tool. J. Mol. Biol. 215, 403-410 (1990).

15 Bradford, P. A. Extended-Spectrum $\beta$-lactamases in the 21st century: Characterization, epidemiology, and detection of this important resistance threat. Clin. Microbiol. Rev. 14, 933-951 (2001).

16 Pitout, J. D., Nordmann, P., Laupland, K. B. \& Poirel, L. Emergence of Enterobacteriaceae producing extended-spectrum $\beta$-lactamases (ESBLs) in the community. J. Antimicrob. Chemother. 56, 52-59 (2005).

17 Aschbacher, R., Doumith, M., Livermore, D. M., Larcher, C. \& Woodford, N. Linkage of acquired quinolone resistance ( $\mathrm{nnrS1}$ ) and metallo-beta-lactamase (blaVIM-1) genes in multiple species of Enterobacteriaceae from Bolzano, Italy. J. Antimicrob. Chemother. $61,515-523$ (2008).

18 Bou, G. et al. Identification and broad disseminatin of the CTX-M-14 $\beta$-lactamases in different Escherichia coli strains in the Northwest area of Spain. J. Clin. Microbiol. 40, 4030-4036 (2002).

19 Oteo, J. et al. Spread of Escherichia coli strains with high-level cefotaxime and ceftazidime resistance between the community, long-term care facilities, and hospital institutions. J. Clin. Microbiol. 44, 2359-2366 (2006).

20 Nüesch-Inderbinen, M. T., Kayser, F. H. \& Hächler, H. Survey and molecular genetics of SHV beta-lactamases in Enterobacteriaceae in Switzerland: two novel enzymes, SHV11 and SHV-12. Antimicrob. Agents. Chemother. 41, 943-949 (1997).

21 Gur, D. et al. Antimicrobial resistance in Gram-negative hospital isolates: results of the Turkish HITIT-2 surveillance study of 2007. J. Chemother. 21, 383-389 (2009).

22 Gur, D. et al. Resistance to newer beta-lactams and related ESBL types in gramnegative nosocomial isolates in Turkish hospitals: results of the multicentre Hitit study. Mikrobiyol. Bul 42, 537-544 (2008).

23 Dağlar, D. et al. Investigation of ESBL types in community acquired urinary Escherichia coli isolates by isoelectric focusing and polymerase chain reaction. Mikrobiyol. Bul 44, 367-374 (2010).

24 Gupta, V. An update on newer $\beta$-lactamases. Indian J. Med. Res. 126, 417-427 (2007). 